\title{
When Collectivism Encountering Individualism in Legal Settings: An Analysis of the CAS Public Hearing Regarding Sun Yang's Case
}

\author{
Jingjing Zhang \\ Department of College English, Zhejiang Yuexiu University, Shaoxing, China \\ Email: 20202104@zyufl.edu.cn
}

How to cite this paper: Zhang, J.J, (2021) When Collectivism Encountering Individualism in Legal Settings: An Analysis of the CAS Public Hearing Regarding Sun Yang's Case. Open Access Library Journal, 8: e7494.

https://doi.org/10.4236/oalib.1107494

Received: May 6, 2021

Accepted: June 26, 2021

Published: June 29, 2021

Copyright () 2021 by author(s) and Open Access Library Inc.

This work is licensed under the Creative Commons Attribution International License (CC BY 4.0).

http://creativecommons.org/licenses/by/4.0/

\section{(c) (i) Open Access}

\begin{abstract}
People's interactions with others are usually reflections of their value, at both individual level and cultural level. In international legal settings where there are designed and professional questions, this is reflected distinctly in the confrontations between two parties. Drawing on the second dimension of Hofstede's value system, namely individualism and collectivism, and taking the first hearing in the CAS arbitration between WADA, Sun Yang and FINA which was held in Switzerland in November 2019 as an example, this paper aims at elaborating on the collectivism-orientated or individualism-orientated values that are reflected in intercultural legal settings. To be more specific, collectivism-orientated value such as "We" Consciousness, Confrontation Avoidance, Facts/Rules Neglecting, High-context Communication and individualism-orientated value like Facts/Rules Focusing were all revealed in the testimony of Chinese witnesses by Sun Yang's party. These values may have led to either negative or positive influence on the efficiency of Chinese witnesses' defence in varying degrees. Analysis in this paper is based on the transcript of the video file of CAS public hearing on Sun's case. I hope that the finding of the research may provide a reference to researchers on cultural values and communications in professional contexts such as international companies, schools, governmental organizations and tribunals.
\end{abstract}

\section{Subject Areas}

Law

\section{Keywords}

Collectivism, Individualism, Legal Settings, Sun Yang's Case, Individualism Index 


\section{Introduction}

Culture, as "one of the two or three most complicated words in the English language" [1], does not only influence what language people speak but also how they speak it. People's interactions with others are deeply, though unconsciously, influenced by the culture where they come from. This is even more evident in intercultural legal contexts, where the parties are opposing in viewpoints and conflict with each other in interests. As it is extraordinarily difficult to understand and accept the way people from another culture communicate and interact, people cannot immediately follow the rule "When in Rome do as the Romans do" in such settings. Taking China's top swimmer Sun Yang's case as an example, this paper aims to answer the following research question: What specific collectivism-orientated or individualism-orientated values are reflected in intercultural legal settings?

\section{Literature Review}

Values forming the core of culture can be revealed in almost every aspect of human activities, especially in intercultural communication. They "tend to be broad-based, enduring, and relatively stable" [2]. Based on the research findings in 1954 by American sociologists Alex Inkeles and Daniel Levinson, Geert Hofstede's value system has been widely applied in diverse areas since the 1980s in and abroad. Despite of its limitations due to the neglect of "value orientation" at individual level and the "changing value heterogeneity" [3], Hofstede's value system is presumably the most often-cited theory in intercultural study. It is applied in wide areas including, but not limited to, translation (Chen, 2012), teaching (Cronje, 2011), conflict management (Tang and Ward, 2003), marketing and advertisement (Torresi, 2010) etc. In recent years, it has been studied as a guide in intercultural company management (Tarique, et al. 2016) and social media (Amaro and Duarte, 2017) and so on. Quantities research bounded to this system demonstrate its dramatic influence on communication. Within the field of interaction in judicial or other formal occasions, including public hearing or trial, studies have been carried out from a perspective of conversational analysis since the 1970s, such as Atkinson and Drew (1979), Sidnell (2004), Heritage and Clayman (2010), and Garcia (2013) etc. or a discourse approach like Scollon and Scollon (1995/2000). Yet applications in those areas involving parties from diverse cultures are less researched. Interactions in such context are dramatically different from and more complicated than ordinary conversations.

As Hofstede suggests, a country's IDV score is associated with "the country's wealth (richer countries associated with higher IDV)" [4]. In other words, economic development is a crucial predictor of individualism-collectivism. In addition, Chen states that "there is strong evidence to suggest that cultures become more individualistic as they become more economically advanced" [5]. Since the past decades, China has made encouraging achievements in economic development. However, that is far from demonstrating the Chinese collectivism- 
oriented values have changed fundamental. Take Sun's case for example, the Chinese witnesses have to cross not only language boundary but also cultural boundary in an individualism dominated context to defend for their party. Based on the research on the interactions of the two parties, the values they revealed are in line with Hofstede's analysis of his survey. Individualism-collectivism dimension is definitely not obsolete or "a failure of analysis" [6], instead, it is still instructive and meaningful to cultural research today, nearly half a century after its birth.

\section{Framework}

The initial survey by Geert Hofstede was carried out in IBM in 1970s in 53 countries and regions and later amounting to over 70. After analyzing the database, Hofstede figured out four dimensions of national values (power distance, individualism-collectivism, masculinity-femininity, and uncertainty avoidance) and later in 1980s the fifth one (long- and short-term orientation) which is based on survey on Chinese values. The case study in this paper draws on individualism-collectivism dimension of Hofstede's value system which is defined as following: "Individualism pertains to societies in which the ties between individuals are loose: everyone is expected to look after him- or herself and his or her immediate family. Collectivism as its opposite pertains to societies in which people from birth onward are integrated into strong, cohesive in-groups, which throughout people's lifetime continue to protect them in exchange for unquestioning loyalty [4].”

This dimension is "the major dimension of cultural variability used to explain cross-cultural differences and similarities" [7], "the most closely linked to a country's level of economic development" [8] and "the most often quoted in the study of cultural patterns" [5]. The reason it is chosen for my analysis is that the cultures involved in Sun Yang's case showed the most dramatic difference on this value dimension compared with the other four. Here are the data on Individualism Index (IDV):

According to Hofstede, the IDV in the United States (where the attorney on behalf of WADA comes from) is 91, the highest among the 76 countries; Besides, the panel president and other two members are all from high IDV countries including UK, France and Italy (all above 70). IDV in China (where Sun and his witnesses are from) is 20 , ranking $58 \sim 63$ among the list and is toward the lower end.

\section{Methodology}

The data used for my analysis is transcribed from the video on YouKu broadcasting the CAS public hearing: WADA vs Sun Yang \& FINA, which was held on Nov. 15th, 2019 in Montreux, Switzerland. The transcription consists of three episodes from the video: 1) Attorney Rychener (attorney by WADA) interrogating Ms. Yang Ming (Sun's mother); 2) Rychener interrogating Mr. Han Zhaoqi 
(vice director of Zhejiang Anti-Doping Agency); and 3) Rychener interrogating Mr. Pei Yang (a law professor from Beijing Normal University who was invited to attend the hearing as an expert witness). The source is open to the public and no ethical issues are involved in the data collection.

The brief background of the case is as following: On Sep. $4^{\text {th }}, 2018$, ITDM was authorized by FINA to have an out-of-competition doping test on Sun Yang, an outstanding Chinese swimmer, which meant Sun's urine and blood sample should be collected. Among the three staff, DCO (Doping control officer), BCA (Blood collection assistant) and DCA (Doping control assistant) who went to Sun's home that night, only the DCO held the authorized certificate, the other two only held a copied and an unauthorized one. Sun doubted their identities and made the samples destroyed after an ineffective communication with the DCO. WADA therefore appealed to the CAS (Court of Arbitration for Sports) on Sun for "violently resisting" the test and FINA for "sheltering" Sun. Sun was suspended from competition for eight years according to the arbitrament award afterwards. However, this award was set aside by Swiss Federal Tribunal in December 2020. According to the media release of CAS in June 2021, the Panel of the second hearing which was held in late May concluded that a period of ineligibility of 4 years and 3 months commencing on 28 February 2020 is to be imposed on Sun Yang.

This paper will focus on a qualitative analysis of this case from a perspective of value dimension. Issues concerning the legal expertise and live interpreting which is criticized for errors and omissions by the public will be excluded in the analysis.

\section{Analysis}

The analysis contains three parts in accordance with the three episodes in appendix. Three Chinese witnesses for Sun's party came from a collectivistic culture while the opposing attorney and the three panel members were all from individualistic cultures, which was clarified in the section of framework. In addition, the hearing was held in Switzerland (IDV = 71) and the official language spoken on site was English, which meant that the physical context of this event was also more prone to individualistic values. To witnesses from a collectivistic culture, it is definitely a challenging task to answer the interrogation of an opposing attorney from an individualistic culture in a context dominated by individualism. At the hearing, both collectivistic and individualistic values were reflected in the three witnesses' interactions with the attorney. These specific values included the "We" Consciousness, Confrontations Avoidance, Facts/Rules Neglecting/Focusing, and High-context Communication.

\subsection{Analysis on Part 1) Attorney Brent Rychener Interrogating Ms. Yang Ming}

In general, Yang's testimony reveled completely collectivism-orientated values: 
The "We" Consciousness, Confrontations Avoidance and Facts/rules neglecting. Most of her answers were long, indirect and irrelevant to the attorney's questions. This may lead to the panel members and the public doubting the credibility of her statements.

a) The "We" Consciousness

In Yang's statement, she emphasized the concept of "We" in her statements in line 30 (omitted in interpreting) and line $43 / 47$ that "we have a video to testify its truth". This indicates that for one thing, the "resources are shared" in "the collectivist family", meaning that the video, as well as the responsibility to tackle the issue, is shared in the family; for another, as a mother from a collectivistic culture, she was exceptionally concerned about Sun's case and even took it as important as her own case. The concept of "We" and "I" may be a mixed concept for her on the spot.

b) Confrontations Avoidance

In this context, Yang certainly knew the importance of answering questions carefully being in the lower level of the hierarchy of power. In majority of her testimony, she offered answers either in the form of "yes plus explanation" (eg. line 9-10 "Yes, let me bring you more details..."; line 16 "Yes, but..."; line 51 "Yes, that...") or the form of "pure explanation" (eg. line 19-20 "I think this is a very critical moment..."; 26-27 "I think it's such an important detail..."; 32-34 "I insist this because..." etc. All these reflected the avoidance of confrontations in collectivistic culture, where "Harmony should always be maintained and direct confrontations avoided. [4]" In collectivistic cultures like China, "The word no is seldom used, because saying "no" is a confrontation" and "the word yes should not necessarily be inferred as an approval, since it is used to maintain the line of communication [4]." Therefore, the "yes" in her statement did not necessarily indicate an approval to the interrogation but may be an acceptable way in her culture to interact smoothly with the attorney. Yang's answers aiming for harmony was not satisfactory and sensible at all to Rychener, whose culture emphasizes that "Speaking one's mind is a characteristic of an honest person [4]". $\mathrm{He}$ either interrupted her to continued his next question as prepared (eg. line 17-18; 52) or to reinforce the present question (eg. line 55). In line 35-36, "I've already said that your son's council can ask you those questions. Yes or no, did you propose calling the police?", he presented his impatience in a direct way.

c) Facts/Rules Neglecting

Phrases like "I think" "I'd like" (eg. line 19-20, 26, 46, 48) were frequently heard in Yang's statements and sometimes she expressed personal judgement (eg. line 53-54 "The fact is that the DCO distorted the truth." This may be an unconscious confrontation of the panel president's statement at the beginning (line 3-4) that she should present the truth, facts and events, instead of impressions or speculations.

What's worth noticing is that, Yang requested several times to be given a few minutes so that she could describe the whole event on the night of out-of-com- 
petition doping control test, almost from the beginning to the end in her testimony. It can be assumed that her request was not objected by any specific person on spot but by the silent context of the public hearing which was dominated by the individualism-oriented value. The hearing procedure and rules are fixed in such legal settings, and it is a general norm to both the attorneys and members of the panel that rules should be followed strictly by every individualistic, with no space for negotiation.

\subsection{Analysis on Part 2) Attorney Brent Rychener Interrogating Mr. Han Zhaoqi}

Comparatively speaking, Han's response to Rychener's questions was the most powerful and efficient in defending for Sun among the three. At least, his responses were not completely shaped by the questions asked. As in such settings, "accusations are led up to, even constructed, from the information obtained in a series of questions and answers" [9]. Both individualistic values like focusing on facts and collectivistic values like sticking to high-context communication were reflected in his testimony.

a) Facts/Rules Focusing

Instead of providing long but irrelevant answers like Yang, Han focused on the questions and gave concise answers, which is in accordance with the rules of the hearing. Examples can be found in line 84 and 95 . Especially when he was asked whether he was aware of Sun had signed both the paperless and paper doping control form, he interacted (line 88) by saying "You told me this fact now."

No expression like "I think" or "I'd like" were contained in his whole defence. Most of his answers presented facts to Sun's advantage and were relevant to the questions. For instance, when he was asked "And are you aware of section 10 of ISTI that says as soon as the sample is collected, it belongs to the testing authority?" (line 96-97), he stated a fact to resist implications that are not in the favor of Sun's party (line 99-100: “The precondition is that the sample must be legally taken by people with the valid qualification and authorization, and then it became a sample for doping control."), rather than a simple Yes or No answer. Similar examples can be found in line 102-105, 107-109, and 112-116. On the other hand, this facts/rules focusing value also exemplified that "cultures tend to be predominately either individualistic or collectivistic, but both cultural tendencies exist in all cultures [7]."

b) High-context Communication

"A low-context communication is one in which the mass of information is vested in the explicit code, which is typical for individualistic cultures [4]." On the contrary, Chinese is a high-context language ("in which most of the information is either in the physical context or internalized in the person, while very little is in the coded, explicit, transmitted part of the message") as "China, the possessor of a great and complex culture, is on the high-context end of the 
scale." while Western culture as American cultural "is toward the lower end of the scale [10]." In other words, Chinese language "tends to be more indirect and relies on more on hearers' inferences [11]" than English language. Han's interaction with the attorney fully indicated this way of communication.

He stated in his responses that "I was not sure at that time." and "I have some knowledge about that international standard." Interestingly, in line 90/91, he substituted the explicit "doping control form the athlete signed" in Rychener's question in line 89 with a more implicit "any doping control documentation" as a way to manage his statement.

\subsection{Analysis on Part 2) Attorney Brent Rychener Interrogating Mr. Pei Yang}

The confrontations between Rychener and Pei mainly focused on the validity of the BCA (Blood collection assistant). Pei was the only one who can speak English among the witnesses therefore could interact with the attorney directly. $\mathrm{He}$ seemed to follow the procedures of the hearing in a correct way, however, as can be seen from part 3 of the appendix, he was gradually led to a disadvantage position in defence by a serious of designed questions.

Facts Neglecting

"By careful construction of questions an attorney can create an impression that is different from the impression that the witness wants to present [9]", yet, to some of those questions, Pei simply provided a yes or no answer (line 124, $127,133,135,138)$ without any further explanation to challenge the assumption underline the question. Nor did he avoid a yes or no answer and state a persuasive fact to challenge the assumption implicitly like Han did. Rychener emphasized on the norm of individualistic culture where truth, laws and rights, and same value standards for everyone is highly considered. He questioned Pei's statements as "personal opinion" for five times in the dialogue (line 128, 132, 142, 150, 153), and three of them were admitted by Pei (line 130, 133, 154).

As facts or truth is "the highest value in the Western philosophical tradition [12]", consequently, to panel members and the public on spot who prone to hold individualistic value, Pei's testimony may be far away from the truth and not reliable.

\section{Discussion}

Various specific values conforming to collectivism or individualism value dimensions were revealed in the testimony of three witnesses, and they certainly had a different effect on the judgement of the panel. Han's testimony, part of which reflected individualistic value was more sufficient and effective than that of the other two. Particularly, Yang's performance at the public hearing is strongly criticized by Chinese public afterwards. Also, in the arbitration report which was released in March 2020 and announced Sun's lose of the case, she was described as "who seems to have played a most unhelpful role to her son". It is 
true that her testimony was not efficient and part of her precious time supposed to presenting the facts that were beneficial to Sun was wasted in requesting for extra time to describe the whole event. That was definitely out of the question to the panel members. However, what has been neglected is firstly, as "perception's about one's culture are mostly unconscious [13]", when people communicate, they do it unconsciously; Secondly, their presentations are deeply rooted in the Chinese culture, and are reflections of their cultural value which is stable and unlikely to change.

\section{Conclusion}

By probing into the confrontations between the two parties in Sun's case, this paper illustrates that values such as the "We" Consciousness, Confrontations Avoidance, Facts/Rules Neglecting, and High-context Communication were reflected in the Chinese witnesses' testimonies. These values are rooted in collectivism-orientated culture and influence the people's way of communication. Although High-context Communication may be applied as a forceful arm to defend, which was picked up by Han in his testimony, majority of the collectivism-orientated values apparently are not recognized in individualism-orientated context thus the consequent result may be far from satisfactory. To achieve effective communication goals, it is conducive for witnesses from collectivistic culture in an individualistic legal context to present statement conforming to the individualistic value, for instance, focusing on facts and truth, and vice versa. What need to be clarified here are: First, the analysis of the case is more focused on the Chinese witnesses' collectivism-orientated cultural background as a whole, their characteristics, experiences, and value orientations as individuals, which also influence their communication styles, are not taken into account; Second, as this is a qualitative analysis, quantitative study shedding light on other formal intercultural contexts such as international companies or schools from cultural or linguistic perspective is worth being explored in modern society. For further research on this case, it may be interesting to investigate into the process and details of the second hearing held in late May 2021 with an entirely new panel appointed.

\section{Conflicts of Interest}

The author declares no conflicts of interest regarding the publication of this paper.

\section{References}

[1] Raymond, W. (1983) Keywords: A Vocabulary of Culture and Society. Fontana, London.

[2] Samovar, L.A., et al. (2017) Communication between Cultures. 9th Edition, Cengage Learning, Boston.

[3] Martin, J.N. and Nakayama, T.K. (2010) Intercultural Communication in Contexts. 5th Edition, McGraw-Hill, New York. 
[4] Hofstede, G., Hofstede, G.J. and Minkov, M. (2010) Cultures and Organizations: Software of the Mind: Intercultural Cooperation and Its Importance for Survival. 2nd Edition, McGraw-Hill, London.

[5] Chen, J.P. (2012) Translation and Intercultural communication. Foreign Language Teaching and Research Press, Beijing.

[6] McSweeney, B. (2002) Hofstede's Model of National Cultural Differences and Their Consequences: A Triumph of Faith-A Failure of Analysis. Human Relations, 55, 89-118. https://doi.org/10.1177/0018726702551004

[7] Gudykunst, W.B. and Kim, Y.Y. (2003) Communicating With Strangers: An Approach to Intercultural Communication. 4th Edition, McGraw-Hill, Boston.

[8] Hofstede, G. (2001) Culture's Consequence: Comparing Values, Behaviours, Institutions, and Organizations across Nations. 2nd Edition, Sega, California.

[9] Garcia, A.C. (2013) An introduction to Interaction: Understanding Talk in Formal and Informal Settings. Bloomsbury Academic, London.

[10] Hall, E.T. (1989) Beyond Culture. Anchor Books, New York.

[11] Zhu, H. (2019) Exploring Intercultural Communication: Language in Action. Routledge, New York.

[12] Du, P. (2015) Intercultural Communication in the Chinese Workplace. Palgrave Macmillan, Basingstoke. https://doi.org/10.1057/9781137381040

[13] Samovar, L.A., et al. (2015) Intercultural Communication: A Reader. 14th Edition, Cengage Learning, Boston. 


\section{Appendix: Video Transcription}

Data source: (Youku) CAS Public Hearing: WADA vs Sun Yang \& FINA.

Place: Montreux, Switzerland Date: Nov. 15th, 2019.

Part 1: Mr. Brent Rychener (Attorney by WADA) VS Ms. Yang Ming (Witness by Sun Yang's party, Sun's mother).

Part 2: Mr. Brent Rychener (Attorney by WADA) VS Mr. Han Zhaoqi (Witness by Sun Yang's party, vice director of Zhejiang Anti-Doping Agency).

Part 3: Mr. Brent Rychener (Attorney by WADA) VS Mr. Pei Yang (Witness by Sun Yang's party, a law professor from Beijing Normal University).

Note: Contents in () are on site interpreting; contents in [ ] are provided by the writer.

\section{Part 1: Mr. Brent Rychener VS Ms. Yang Ming}

President: Ok, We start with Ms. Ming Yang. Welcome here. Ok, we start with Ms. Ming Yang. Welcome here. Thanks for coming. And I remind you that you have to tell us all the truth, you have to talk about facts, events, not talking about your impressions, your speculations.

Rychener: And you say in that paragraph that the doping control officer initially agreed that Sun Yang could go to the bathroom alone?

Yang: 是的,我解释一下啊,当时的情况是这样的。就是在 12 点 10 分左右, 我把我的电话给了中国游泳队的领队程浩, 然后程浩要求跟主检官通话将近 10 分钟。 (Yes, let me bring you more details on what I have seen that night. At about 12:10 that night, I handed over my phone to the Chinese swimming national team manager Mr. Cheng Hao, and asked him to talk directly with the DCO.)

Rychener: That was not response to my question. My question was you say that doping control officer initially agreed that Sun Yang could go to the bathroom alone but then she changed her mind. Is that what you said in your statement?

Yang: 是的,但是... (Yes, but...) [Interrupted by Rychener].

Rychener: So you understand that the doping control officer objected to your son going to the bathroom alone?

Yang: 因为这个问题我觉得非常重要,所以我想把当时的情况, 就是叙述一 遍。( I think this is a very critical moment in the whole event. That's why I'd like to give you more details if you allow me to do so.)

Rychener: Your attorney will be allowed to ask you questions. So after your son went out to the bathroom, and the DCO objected to your son going to the bathroom alone, you ran and told your son to stop. Correct?

Yang: 我觉得, 这个问题......因为这个问题非常重要,所以我想请仲裁包括 律师让我把当时的情况叙述一下。 (I think it's such an important detail which why I hope that the panel could allow me to provide more details here to answer your questions fully.) 
Rychener: I only have a limited amount of time. So I'll let your son's attorney to ask you that question. So after that you proposed calling the police, right?

Yang: 因为就是,主检官提供的证词,通过我们的视频 [参照],完全是不一样, 所以我觉得这个是关键, 今天就应该在这个场面,仲裁庭都在的情况下, 我把这 个事情、当时的情况说清楚。(I insist this because I found the testimony made by the DCO on the video was completely different from what had happened that night, that's why I insist to continue my description to give you the truth.)

Rychener: I've already said that your son's council can ask you those questions. Yes or no, did you propose calling the police?

Yang: 我说是,我要报警,不是说给警察打电话。因为当时她同意孙杨去卫生 间。(I said yes. I said that I'll report to the police. Because at that time that she gave her approval to Sun Yang to go to the toilet by himself.

Rychener: In paragraph 17 of your statement, you say that the doping control officer proposed to take the blood sample to leave, is that correct?

Yang: 所以这个问题又跟刚才这个,就是关于去尿检这个时间 [口误],这个问 题是一样的,所以我请仲裁庭让我把当时这个情况花几分钟说完。因为我们是 有视频来作证, 就是佐证这个事情的真实性,而对方尿检官 [口误],啊不是,那个 主检官恰恰是什么啊, 就是跟事实不符。这是很严重的问题,所以今天,我想把 这个事情说清楚。(So similarly this question is the same as the one on the urine test. I'd like to request that I am allowed to explain the situation in a few minutes. Because we have a video to testify its truth. What the DCO said is totally different from the truth. This is a severe problem, so I'd like to clarify the event here today.)

Rychener: And when the guard brought back the broken container, the DCO asked to take a picture of it. And Dr. Ba Zhen would not let her take a picture, correct?

Yang: 是的。那是...... (Yes, that...) [Interrupted by Rychener].

Rychener: And then your son tore up the doping control form, correct?

Yang: 是这样的,主检官在报告中,她那个,完全歪曲事实,因为当时...(The fact is that the DCO distored the truth. At that night...) [Interrupted by Rychener].

Rychener: Did your son tore up the doping control form?

Yang:...那个检查单就放在孙杨面前,而且没有讲义夹之类的,就是一张纸。但 是那个主检官她叙述的是有讲义夹,孙杨冲到那边去抢, 因为我们的视频里面, 完全是可以证实。(The situation was the Doping Control Form was right in front of my son and the DCO mentioning in her report that the DCF was actually attached to a binder, actually there was no binder. It's just a paperwork in front of my son.)

Rychener: Your son tore up the doping control form that he had signed earlier, correct?

Yang: 不是的, 不是像那个主检官那样叙述的。因为就在他座位的面前, 他觉 得检查结束了我把这个拿走, 我觉得这个很正常。跟主检官叙述当中孙杨在她 的讲义夹里面去抢什么东西, 完全意思是不一样的,跟事实完全不符的。这个有 
视频作证, 有视频, 有视频。(It's different from the DCO's description. The DCF was in front of Sun Yang at the desk and we think it's his natural reaction after the sample collection. And he just took away his form which is completely different from what the DCO said in the report where Sun Yang tried to take the DCF from the binder from her and tried to rip it off.)

$\cdots$

President: Madam Yang, thank you very much for coming.

Yang:我都没讲完呢。(I’m not finished yet.)

President: Thanks for your testimony. You are free to go. Thank you.

Yang:我还没说完呢。我, 我觉得我可不可以申请一下,当时因为这个尿检 的情况,我觉得这个情况应不应该那个... 都没说完就让我走了。 [I haven't finished yet. Can I, can I request that, as I think the situation on urine test should be...I'm asked to leave without finishing my statement.]

\section{Part 2: Mr. Brent Rychener VS Mr. Han Zhaoqi}

President: Ok, welcome, Dr. Zhaoqi. Thanks for coming. And I remind you first of all that as witness, you have to tell us first of all, all the truth, you have to talk about facts, events, by abstaining from expressing opinions and speculations.

$\cdots$

Rychener: And you are aware that Sun Yang had signed the doping control form indicating that he had been notified and that he understood that any refusal could make considered an anti-doping rule violation?

Han: 这个我不是很清楚。( I was not sure at that time.)

Rychener: Do you know that's true now? I can show you the document that he signed. He initially signed paperless doping control form, then he signed the paper doping control form. Are you aware of that now?

Han: 你[现在]告诉我了。( You told me this fact now.)

Rychener: So you've never been shown the doping control form the athlete signed?

Han: 有没有签过相应的文件我不是很清楚,但是我知道孙杨被一个没有血 检官资格又没有授权的人抽了血。(I didn’t know whether Sun Yang had singed any doping control documentation, that's what I could say. However, what I knew that night is blood sample is taken from Sun Yang by a doping control assistant without appropriate qualification and without appropriate authorization.)

Rychener: Are you familiar with the international standard for testing and investigations?

Han: 我还是了解一些的。(I have some knowledge about that international standard.)

Rychener: And are you aware of section 10 of ISTI that says as soon as the sample is collected, it belongs to the testing authority?

Han: 那是要合法的。首先要有一个前提,具有血检官资格的人得到授权以 
后,才能成为兴奋剂的血样。(The precondition is that the sample must be legally taken by people with the valid qualification and authorization, and then it became a sample for doping control.)

Rychener: Dr. Zhaoqi, you stated in your statement that you have received anti-doping training?

Han: 对的,我们中国非常重视反兴奋剂知识的教育,我们经常会开展相关的 反兴奋剂的教育活动。我也曾经参加过多次。(Yes, because Chinese government paid great attention to the anti-doping education. And many anti-doping programme and activities were conducted on regular basis and I had the honor to participate some of them.)

Rychener: In your aware though, IDTM is not bond to follow CHINADA guidelines, right?

Han: 中国反兴奋剂中心也是按照 WADA 的国际标准来执行的,不存在中 国反兴奋剂中心单独的标准。[CHINADA's operations all follow the requirements in WADA code and in ISTI. There is no separate CHINADA codes.]

$\cdots$

Rychener: But that's not required by the ISTI, is it?

Han: 国际要求的标准是每一个兴奋剂的检察官都必须接受相应的兴奋剂 的培训,要获得资格,要再认证。要取得资格以后才能被授权。没有资格的人是 不能够被授权其进行兴奋剂检查的。(According to the requirement of ISTI, the DCO must receive relevant training to get a qualification and readapted by anti-doping organization to make sure that they are qualified to conduct the doping control test.)

\section{Part 3: Mr. Brent Rychener VS Mr. Pei Yang}

President: Professor Pei Yang, welcome. Thanks for coming. And I remind you as all the other witnesses that you need to tell us all the truth, you have to talk about facts, not talk about your speculations or personal impressions that no relevant to the cord.

Rychener: You agreed in that paragraph that the blood collection assistant is a registered nurse holding a valid PNC, correct?

Pei: Yes.

Rychener: So that issue your are addressing in your report is, if a nurse has a valid PNC, but doesn't show it to the athlete at the time the sample collected, correct?

Pei: Yes.

Rychener: So you are giving a personal opinion about there is a criminal violation even though it's not addressed in any Chinese law, regulation, or diagnosis or treatment norms, correct?

Pei: Yes, But I am talking about the liability without qualification, but not without the certificate. I mean, even if you hold a certificate, but you didn't show it, it means that you are not qualified. 
Rychener: And that's your personal opinion?

Pei: Yes.

Rychener: So a picture would not satisfy it?

Pei: No.

Rychener: Are you familiar with the practices that CHINADA follows when it collects blood samples?

Pei: No.

Rychener: So are you saying that if CHINADA collects blood samples without showing the original of the nurse's PNC, that CHINADA is committing a criminal violation every time?

Pei: I just answer your question and give my opinion according to Chinese law.

Rychener: But is it your opinion that every time anybody collects the blood sample without showing the actual PNC not a copy or a photo, that's a criminal violation?

Pei: I just say, it may be criminal liability, it depends on.

Rychener: Are you aware that the blood collection nurse in this case said that she did have a picture of her PNC on her phone that night?

Pei: No, I didn't.

Rychener: Are you aware whether anybody ever request to see her PNC that night?

Pei: I don't know the situation.

Rychener: So you are giving an opinion that she committed a criminal act and you don't know whether anybody asked to see her PNC?

Pei: I've been just asked to by the council of the athlete to examine the qualification of the nurse.

Rychener: But you gave an opinion that she might be subject to imprisonment.

Pei: Yes, it's a possibility.

Rychener: And you don't know whether anybody even asked to see it?

Pei: No. 